\title{
Optimasi Jumlah Produksi dan Biaya Distribusi UMKM Semprong Amoundy Menggunakan Metode Simpleks dan Algoritma Greedy
}

\author{
Resa Nofatiyassari ${ }^{1}$, Rianita Puspa Sari ${ }^{2 *}$ \\ 1,2 Teknik Industri, Universitas Singaperbangsa Karawang \\ Jl. H.S. Ronggowaluyo Kel. Puseurjaya Kec. Telukjambe Timur, Karawang, 41361, Indonesia \\ ${ }^{1}$ resa.nofatiyassari17005@student.unsika.ac.id \\ 2*rianita.puspasari@ft.unsika.ac.id
}

\section{Optimization Total Production and Distribution Costs of Semprong Amoundy MSME's Using the Simplex Method and Greedy Algorithm}

Dikirimkan: 01, 2021. Diterima: 03, 2021 Dipublikasikan : 03, 2021.

\begin{abstract}
Production optimization must be considered in order to get the optimal amount of production, which is related to company profit. In addition, the distribution route that is not optimal will also cause production costs to expand. These two things are the main problems faced by Semprong Amoundy MSMEs that have not paid attention to optimization of production and optimization of distribution routes. The purpose of this research is to find the optimal solution of the number and type of semprong production to maximize the income of Amoundy MSMEs, and to find a solution for the shortest distribution route to minimize distribution costs of semprong products. The method used to solve this problem is Simplex Method and Travelling Salesman Problem with the Greedy Algorithm approach. The research resulted the decision that Amoundy MSMEs had to produce 18 boxes of large packaged semprong every day to generate maximum income. The distribution route that must be taken to minimize distribution costs is Amoundy House Production - Bontot Delajaya Shop - Erik Shop - Denpasar Shop - Aneka Shop - Oleh-oleh Karawang Outlet - Amoundy House Production, estimated distribution cost of Rp. 20,120.-
\end{abstract}

Keywords - Production Optimization; Simplex Method; Traveling Salesman Problem.; MSME; Greedy Algorithm.

\begin{abstract}
Abstrak- Optimasi produksi perlu diperhatikan agar didapatkan jumlah produksi yang optimal, yang mana hal ini akan berhubungan dengan profit perusahaan. Selain itu rute distribusi yang belum optimal juga akan menyebabkan pembengkakan biaya produksi. Kedua hal ini merupakan masalah utama yang dihadapi oleh UMKM Semprong Amoundy yang belum memperhatikan optimasi produksi dan optimasi rute distribusi. Tujuan dilakukannya penelitian ini yaitu untuk mencari solusi optimal dari jumlah dan jenis produksi semprong untuk memaksimalkan pendapatan UMKM Amoundy, serta mencari solusi rute distribusi terpendek untuk meminimalkan biaya pendistribusian produk semprong. Metode yang digunakan untuk adalah Metode simpleks dan Travelling Salesman Problem dengan pendekatan algoritma greedy. Penelitian menghasilkan keputusan bahwa UMKM Amoundy harus memproduksi 18 box kue semprong kemasan besar setiap hari untuk menghasilkan pendapatan maksimal. Rute distribusi yang harus ditempuh untuk meminimalkan biaya distribusi yaitu Rumah Produksi Amoundy - Toko Bontot Delajaya - Toko Erik - Toko Denpasar - Toko Aneka - Outlet Oleh-oleh Karawang - Rumah Produksi Amoundy dengan taksiran biaya distribusi sebesar Rp. 20,120.-

Kata kunci- Optimasi Produksi; Metode Simpleks; Travelling Salesman Problem; UMKM; Algoritma Greedy.
\end{abstract}




\section{PENDAHULUAN}

Eksistensi Usaha Mikro Kecil dan Menengah (UMKM) di Indonesia tidak dapat diremehkan atas peran strategis dengan kontribusinya pada sektor ekonomi Negara Indonesia. Peran strategis UMKM, antara lain: 1) Menyerap tenaga kerja; 2) Sebagai penghasil produk berupa barang dan jasa pada tingkat harga yang terjangkau bagi rakyat berpenghasilan rendah; dan 3) Penghasil devisa Negara yang potensial karena keberhasilannya dalam memproduksi komoditi non migas [1]. Berdasarkan apa yang tertulis dalam UndangUndang Nomor 20 Tahun 2008, Usaha Mikro Kecil dan Menengah (UMKM) adalah jenis usaha kecil yang memiliki kekayaan bersih paling banyak Rp 200.000.000, kekayaan tersebut belum termasuk tanah dan bangunan tempat usaha, serta usaha yang berdiri sendiri. Menurut KemenkopUKM 2018, UMKM menyumbang PDB atas dasar harga berlaku sebesar $61.07 \%$ secara nasional [2]. Adanya kontribusi besar UMKM terhadap perekonomian yang bersanding dengan semangat pembangunan usaha UMKM oleh masyarakat akan berujung sia-sia, jika tidak memiliki going concern yang baik [3]. Terutama di tempat yang memiliki potensi baik untuk pertumbuhan ekonomi. Salah satunya adalah Kabupaten Karawang yang dijuluki sebagai Kota Industri.

Jumlah penduduk Kabupaten Karawang menurut Badan Statistik Pusat Kabupaten Karawang tahun 2020 sebanyak 2.37 juta, dengan persentase penduduk miskin hanya $10.15 \%$ pada tahun 2015. Hal ini mengindikasikan bahwa potensi pengembangan UMKM di Kabupaten Karawang memiliki peluang berkembang yang baik. Data Tahun 2015, Kabupaten Karawang mengalami peningkatan jumlah UMKM sebesar 14. 183 jika dibandingkan Tahun 2012 [4]. UMKM di Kabupaten Karawang bergerak pada banyak bidang, salah satunya yaitu bidang minuman dan makanan. Kabupaten Karawang memiliki banyak panganan yang digemari masyarakat, salah satu panganan yang terkenal akan rasanya yang enak adalah semprong. Semprong merupakan panganan yang umumnya memiliki rasa yang tidak terlalu manis, memiliki aroma khas, renyah dan tekstur permukaan yang halus, dengan warna kuning kecoklatan yang berbentuk gulungan dan ada pula yang berbentuk segitiga serta persegi panjang [5].

Setiap perusahaan secara langsung memiliki keterbatasan dalam mencapai tujuannya [6]. UMKM semprong Amoundy memiliki tujuan untuk memaksimalkan pendapatan penjualan dan meminimasikan biaya distribusi yang selama ini belum pasti. UMKM Amoundy merupakan salah satu UMKM di Kabupaten Karawang yang bergerak di bidang makanan dan bersifat home industry. UMKM Amoundy terletak di Jalan Singasari, Karawang Kulon, Kecamatan Karawang
Barat, Kabupaten Karawang. Produk yang dihasilkan oleh UMKM Semprong Amoundy hanya sebatas kue semprong dan tidak memiliki jenis produk yang lain. Proses produksi melibatkan 20 tenaga kerja yang bertugas di dapur produksi. Sedangkan dalam proses pembuatan adonan, dilakukan oleh pemilik UMKM karena resep kue semprong Amoundy merupakan rahasia dapur yang telah turun temurun. UMKM Semprong Amoundy memproduksi kue semprong dan dijual dalam kemasan kecil, kemasan sedang dan kemasan besar dengan harga yang berbeda. Untuk kue semprong Amoundy kemasan kecil dihargai Rp. 35,000, harga untuk kemasan sedang yaitu Rp. 50,000 dan harga untuk kemasan besar adalah Rp. 100,000. Pada studi kasus home industry ini optimasi perencanaan produksinya masih kurang optimal dikarenakan keterbatasan sumber daya, modal, dan pemasaran. Selain itu, UMKM ini juga mendistribusikan produk ke lima toko oleh - oleh di beberapa daerah di Kabupaten Karawang. Namun, pendistribusian tersebut masih belum optimal karena belum ditemukan rute pendistribusian yang tepat, yaitu rute distribusi paling pendek yang dapat menghubungkan sumber ke tujuan. Pendeknya rute distribusi yang digunakan oleh UMKM Amoundy tentu berdampak pada biaya distribusi yang akan tereduksi dan menjadi lebih murah.

Selama ini, UMKM dalam melakukan produksi dan distribusi hanya menggunakan metode perkiraan tentang berapa jumlah produk yang harus di produksi dan rute distribusi yang akan ditempuh tanpa menggunakan data. UMKM Amoundy merupakan salah satu UMKM yang menerapkan metode perkiraan tersebut. Metode perkiraan tanpa menggunakan data yang ada akan berpengaruh pada pendapatan dan pengeluaran UMKM Amoundy. Hal inilah yang mendasari dilakukannya penelitian optimasi ini. Dalam melaksanakan penelitian, dibutuhkan suatu alat atau metode yang dapat mendukung tujuan penelitian. Metode yang digunakan yaitu linear programming metode simpleks dan travelling salesman problem menggunakan pendekatan algoritma greedy.

Linear programming metode simpleks digunakan untuk mengetahui jumlah dan jenis semprong yang harus diproduksi, sehingga dapat mencapai pendapatan penjualan yang tinggi. Metode simpleks merupakan suatu metode penentuan solusi optimal dengan cara kerja memeriksa titik ekstrim satu per satu secara bertahap dengan perhitungan iterasi, hingga didapatkan keputusan yang optimal [7]. Metode simpleks yaitu teknik optimasi yang sangat aplikatif pada permasalahan yang menyangkut pengoptimalan, baik itu maksimal atau minimal [8]. Referensi [8] menunjukan bahwa syarat yang harus 
dipenuhi agar metode simpleks dapat digunakan yaitu, suatu studi kasus harus memiliki nilai fungsi tujuan, sumber harus merupakan persediaan terbatas, dan harus dapat menyatakan tujuan dan pembatasnya dalam model matematika. Penggunaan linear programming metode simpleks berperan untuk menemukan nilai optimum dari fungsi tujuan linier pada kondisi pembatasan (constraints) tertentu [9]. Harga penjualan ditetapkan sebagai fungsi tujuan, sedangkan jumlah bahan baku dan waktu produksi ditetapkan sebagai fungsi batasan.

Prinsip ekonomi pasti akan selalu menjadi pegangan bagi setiap pelaku usaha. Prinsip ekonomi yang digubah yaitu usaha atau modal sedikit mampu menghasilkan keuntungan besar. Hal ini yang memicu munculnya masalah optimasi [10]. Kunci untuk mendapatkan laba yang maksimal bagi suatu usaha, baik UMKM maupun perusahaan besar yaitu dengan penentuan jumlah produksi yang tepat [11]. Pemanfaatan sumber daya yang dimiliki UMKM menjadi poin penting dalam melakukan optimasi produksi.

Selain upaya mengoptimalkan produksi, pengaturan distribusi dan transportasi juga harus dilakukan untuk meminimalisasi jumlah cost distribusi yang diperlukan. Definisi transportasi pada kasus ini yaitu, suatu perpindahan barang komoditas dari tempat satu ke tempat lain, atau dari tempat asal (gudang) ke tempat tujuan yang telah ditentukan (konsumen) [12]. Distribusi atau dikenal sebagai saluran pemasaran pada prinsipnya adalah aliran barang dari produsen ke konsumen melalui lembaga pemasaran [13]. Distribusi adalah suatu jalur yang dilalui oleh arus barang-barang dari produsen ke perantara dan akhirnya sampai pada pemakai [14]. Saluran distribusi yang tidak efektif akan berimbas pada biaya yang harus dikeluarkan dan menjadi masalah bagi produsen. Ada beberapa model yang dapat digunakan untuk mencari rute optimal, yaitu model shortest route dan travelling salesman problem (TSP). Shortest Route hanya berfokus bagaimana caranya sampai pada titik tujuan dengan rute sesingkat mungkin tanpa peduli berapa tempat atau titik yang ada. Shortest Route hanya memiliki 2 titik yang paling penting, yaitu titik asal dan titik tujuan. Travelling Salesman Problem merupakan suatu metode yang digunakan untuk mencari rute terdekat dengan melibatkan seluruh titik yang ada, karena tujuannya yaitu singgah di setiap titik. Pengoptimalan cost dan rute distribusi produk kue semprong yang diteliti termasuk dalam model travelling salesman problem (TSP).

Travelling Salesman Problem (TSP) merupakan salah satu permasalahan optimasi yang biasa terjadi, pencarian solusi Travelling Salesman
Problem (TSP) hanya dapat diperoleh dengan mencoba beberapa kemungkinan secara acak [15]. Permasalahan TSP berfokus pada seseorang yang harus mengunjungi semua kota tepat satu kali dan kembali ke kota asal [16]. Tujuannya untuk mencari rute terdekat menuju tempat - tempat distribusi produk agar dapat meminimalisir cost yang digunakan dalam pembiayaan transportasi. Penelitian ini menggambarkan jalur distribusi produk kue Semprong Amoundy pada 5 titik lokasi tujuan. Metode yang digunakan untuk memecahkan model travelling salesman problem (TSP) yaitu algoritma greedy. Algoritma greedy merupakan suatu algoritma yang dapat digunakan untuk memecahkan masalah secara bertahap, dengan cara mengambil suatu pilihan terbaik yang diperoleh pada saat itu yang diistilahkan optimum local [17]. Prinsip yang diterapkan pada algoritma greedy adalah take what you get now!, tidak ada waktu untuk kembali memeriksa ke belakang atau ke depan [17].

Referensi [9] merupakan penelitian terdahulu yang digunakan sebagai acuan, penelitian tersebut menunjukan bahwa peneliti menggunakan metode simpleks untuk memecahkan masalah maksimasi keuntungan dagang usaha martabak Sucipto. Penggunaan metode simpleks efektif untuk memecahkan masalah yang melibatkan dua atau lebih variabel dan menghasilkan solusi yang optimum sesuai dengan yang diinginkan. Penelitian yang berkaitan dengan pencarian optimasi rute distribusi mengacu pada penelitian yang dilakukan oleh Bolanos [18]. Referensi [15] menunjukan bahwa Bolanos memecahkan permasalahan model travelling salesman problem menggunakan algoritma genetika. Hasil penelitian yang dilakukan menunjukkan bahwa efisiensi dari algoritma menggabungkan teknik dan struktur lingkungan, yang mana hal ini memberikan solusi yang berkualitas baik pada setiap iterasi algoritma. Kekurangan pada penelitian ini yaitu dalam penyelesaian masalahnya diperlukan generasi yang banyak untuk menghasilkan sebuah nilai yang optimal. Penggunaan algoritma greedy merupakan cara pemecahan masalah yang lebih cepat dan lugas dari algoritma lainnya, serta aproksimasi keputusan yang dihasilkan layak dipakai untuk hasil optimum yang diinginkan.

Penelitian ini bertujuan untuk menentukan optimasi pengalokasian bahan baku dan waktu produksi guna mendapatkan jumlah produksi yang optimal sehingga dapat memaksimalkan penjualan dan mencapai hasil yang diharapkan. Selain untuk memaksimalkan produksi, penelitian juga bertujuan untuk mengoptimalkan penentuan suatu lintasan yang menghubungkan sumber ke tujuan distribusi sehingga biaya yang berkaitan dengan 
tiap-tiap cabang dan lintasan adalah biaya yang paling minimum.

\section{Metodologi PenElitian}

Metode penelitian menggunakan pendekatan kuantitatif. Metode penelitian kuantitatif adalah suatu cara atau pendekatan yang digunakan untuk memecahkan masalah penelitian yang berkaitan dengan data berupa angka dan program statistik [15]. Teknik pengambilan data menggunakan metode wawancara langsung dengan pemilik rumah produksi kue semprong Amoundy, sehingga data yang digunakan merupakan data primer. Penelitian dilakukan dengan metode Simpleks dan Algoritma Greedy.

Langkah-langkah yang diterapkan dalam melakukan operasi pemecahan masalah menggunakan metode simpleks menurut [8] yaitu:

a) Fungsi tujuan diubah menjadi fungsi persamaan nol (persamaan implisit), fungsi pembatas atau kendala diubah ke dalam bentuk persamaan dengan menambahkan "slack variable".

b) Langkah pembentukan tabel atau proses iterasi memuat variabel $\mathrm{Z}$ (variabel tujuan) dan variabel tambahan pada kolom dasar. Setiap koefisien variabel $\mathrm{Z}$ dan koefisien variabel tambahan dimasukan ke dalam tabel sesuai model persamaan yang telah disusun.

c) Langkah penentuan kolom pivot (kolom kunci). Kolom pivot tergantung pada bentuk tujuan, bentuk tujuan pada penelitian ini adalah optimasi maksimal, maka kolom pivot yang dipilih adalah kolom dengan koefisien negatif terbesar.

d) Langkah penentuan baris pivot (baris kunci). Penentuan baris kunci didasarkan pada suatu baris yang memiliki nilai terkecil pada rasio antara elemen kolom b dengan kolom pivot.

e) Langkah mengubah elemen pada baris pivot. Pengubahan pada baris pivot dilakukan menerapkan operasi hitung metode Gauss Jordan 1.

f) Langkah mengubah elemen baris lainnya. Pengubahan elemen pada baris lainnya berbeda dengan pengubahan elemen pada baris pivot. Metode yang digunakan pada pengubahan elemen baris lain adalah metode Gauss Jordan 2.

Penentuan rute distribusi terpendek menggunakan metode algoritma greedy. Berikut langkah yang dilakukan dalam menggunakan algoritma greedy [16]: a) Tentukan tempat awal dimulainya perjalanan.

b) Tentukan tempat yang menjadi tujuan selanjutnya, tempat tersebut berjarak paling dekat dengan tempat awal.

c) Tentukan tempat berikutnya yang terdekat hingga tempat tujuan terakhir.

d) Kembali ke kota awal dan jumlahkan seluruh jarak yang ditempuh.

\section{HASIL PENELITIAN}

\section{A. Pengumpulan Data}

Pada pengumpulan data, data diperoleh dari hasil wawancara dan studi lapangan secara langsung di UMKM Amoundy. Tabel I menyajikan data harga jual, jumlah bahan baku yang digunakan dan jam kerja karyawan dalam proses produksi semprong.

TABEL I

DATA HARGA JUAL, KEBUTUHAN DAN WAKTU

\begin{tabular}{lcccc}
\multicolumn{5}{c}{ PEMBUATAN PRODUK } \\
\hline $\begin{array}{c}\text { Jenis } \\
\text { Kemasan }\end{array}$ & $\begin{array}{c}\text { Harga } \\
\text { Jual } \\
(\mathbf{R p})\end{array}$ & $\begin{array}{c}\text { Telur } \\
(\mathbf{K g})\end{array}$ & $\begin{array}{c}\text { Tepung } \\
(\mathbf{K g})\end{array}$ & $\begin{array}{c}\text { Waktu } \\
\text { Operasi } \\
(\mathbf{J a m})\end{array}$ \\
\hline $\begin{array}{l}\text { Box } \text { Kecil } \\
\left(\mathrm{X}_{1}\right)\end{array}$ & 35,000 & 3 & 5 & 3 \\
$\begin{array}{l}\text { Box } \\
\text { Medium }\end{array}$ & 50,000 & 2 & 4 & 2 \\
$\left(\mathrm{X}_{2}\right)$ & & & & \\
Box \\
$\begin{array}{l}\text { Medium } \\
\left(\mathrm{X}_{3}\right)\end{array}$ & 100,000 & 2.5 & 4 & 2 \\
\hline
\end{tabular}

Tabel II menyajikan data jarak rute yang harus di tempuh saat pendistribusian produk kue semprong Amoundy.

TABEL II

JARAK TEMPUH DISTRIBUSI PRODUK (DALAM

\begin{tabular}{ccccccc}
\multicolumn{7}{c}{ SATUAN KM) } \\
\hline Lokasi & A & B & C & D & E & F \\
\hline A & 0 & 1.3 & 2.2 & 1.5 & 1.6 & 2.1 \\
B & 1.3 & 0 & 1.3 & 1.5 & 0.75 & 2.4 \\
$\mathbf{C}$ & 2.2 & 1.3 & 0 & 0.21 & 2.1 & 3.4 \\
$\mathbf{D}$ & 1.5 & 1.5 & 0.21 & 0 & 2.3 & 3.6 \\
$\mathbf{E}$ & 1.6 & 0.75 & 2.1 & 2.3 & 0 & 2.1 \\
$\mathbf{E}$ & 2.1 & 2.4 & 3.4 & 3.6 & 2.1 & 0 \\
\hline \multicolumn{7}{c}{ Sumber : Google Maps (2019) }
\end{tabular}

Ketarangan notasi:

A : Rumah produksi kue semprong Amoundy;

B : Toko Bontot Delajaya;

C : Toko Denpasar;

D : Toko Aneka;

E : Toko Erik;

F : Outlet oleh - oleh Karawang. 


\section{B. Persamaan}

Persamaan matematika dari data yang diperoleh adalah sebagai berikut:

Tujuan

$$
Z=X_{1}+X_{2}+X_{3}
$$

Pembatas

$$
x_{1}+x_{2}+x_{3} \leq b
$$

Penentuan Rute Terdekat

$$
X_{1}+X_{2}+X_{3}+X_{4}+X_{5}+X_{6}=Z
$$

\section{Penyelesaian Metode Simpleks}

Sesuai dengan syarat yang harus dipenuhi dalam metode simpleks, yaitu adanya batasan masalah. Tabel III menyajikan jumlah kebutuhan dan persediaan maksimum sumber daya pada UMKM Amoundy.

TABEL III

KEBUTUHAN BAHAN BAKU DAN JAM KERJA PEMBUATAN PRODUK

\begin{tabular}{lccc}
\hline \multicolumn{1}{c}{ Jenis Produk } & $\begin{array}{c}\text { Telur } \\
(\mathbf{k g})\end{array}$ & $\begin{array}{c}\text { Tepung } \\
(\mathbf{k g})\end{array}$ & $\begin{array}{c}\text { Jam Kerja } \\
(\mathbf{j a m})\end{array}$ \\
\hline Box Kecil $\left(\mathrm{X}_{1}\right)$ & 3 & 5 & 3 \\
Box Medium $\left(\mathrm{X}_{2}\right)$ & 2 & 4 & 2 \\
Box Medium $\left(\mathrm{X}_{3}\right)$ & 2.5 & 4 & 2 \\
Persediaan & 45 & 75 & 42 \\
Maksimum & & & \\
\hline
\end{tabular}

Penotasian ke dalam bentuk matematika

Fungsi tujuan keuntungan :

$$
\begin{aligned}
& Z=X_{1}+X_{2}+X_{3} \\
& Z=35 X_{1}+50 X_{2}+100 X_{3}
\end{aligned}
$$

Kendala atau pembatas :

$$
\begin{aligned}
& X_{1}+X_{2}+X_{3} \leq X \\
& 5 x_{1}+3 x_{2}+4 x_{3} \leq 75 \\
& 3 x_{1}+2 x_{2}+2.5 x_{3} \leq 45 \\
& 3 x_{1}+2 x_{2}+2 x_{3} \leq 42
\end{aligned}
$$

Penulisan MPL baku

$$
5 x_{1}+3 x_{2}+4 x_{3}+x_{4} \leq 75
$$

$3 x_{1}+2 x_{2}+2.5 x_{3}+x_{5} \leq 45$

$3 x_{1}+2 x_{2}+2 x_{3}+x_{6} \leq 42$

$Z=35 x_{1}+50 x_{2}+100 x_{3}+0 x_{4}+0 x_{5}+0 x_{6}$

Basis langkah nol

Tabel IV menyajikan langkah nol sebelum dilakukan operasi hitung.
TABEL IV

\begin{tabular}{cccccccc}
\multicolumn{8}{c}{ LANGKAH NOL } \\
\hline Basis & $\mathrm{X}_{1}$ & $\mathrm{X}_{2}$ & $\mathrm{X}_{3}$ & $\mathrm{X}_{4}$ & $\mathrm{X}_{5}$ & $\mathrm{X}_{6}$ & $\mathrm{~b}$ \\
\hline $\mathrm{X}_{4}$ & 5 & 3 & 4 & 1 & 0 & 0 & 75 \\
$\mathrm{X}_{5}$ & 3 & 2 & 2.5 & 0 & 1 & 0 & 45 \\
$\mathrm{X}_{6}$ & 3 & 2 & 2 & 0 & 0 & 1 & 42 \\
$\mathrm{Cj}$ & 35 & 50 & 100 & 0 & 0 & 0 & \\
\hline
\end{tabular}

$\mathrm{X}_{3}$ : Variabel masuk

$\mathrm{X}_{5}$ : Variabel keluar

Perhitungan iterasi I

$$
\text { a) } \begin{aligned}
& x_{3 \text { Baru }} \\
& \frac{1}{\text { pivot }} \times x_{5 \text { lama }} \\
& \frac{1}{2.5} X(3 ; 2 ; 2.5 ; 0 ; 1 ; 0 ; 45) \\
= & (1.2 ; 0.8 ; 1 ; 0 ; 0.4 ; 0 ; 18)
\end{aligned}
$$

b) $x_{4 \text { Baru }}$

$-\left[\frac{\text { variabel asosiasi }}{\text { pivot }}\right] \times$ variabel keluar + xbaris lama

$=[-1.6] \times(3 ; 2 ; 2.5 ; 0 ; 1 ; 0 ; 45)+$

$(5 ; 3 ; 4 ; 1 ; 0 ; 0 ; 75)$

$=(0.2 ;-0.2 ; 0 ; 1 ;-1.6 ; 0 ; 3)$

c) $x_{6 \text { Baru }}$

$-\left[\frac{\text { variabel asosiasi }}{\text { pivot }}\right] \times$ variabel keluar + xbaris lama

$=[-0.8] \times(3 ; 2 ; 2.5 ; 0 ; 1 ; 0 ; 45)+$

(3; $2 ; 2 ; 0 ; 0 ; 1 ; 42)$

$=(0.6 ; 0.4 ; 0 ; 0 ;-0.8 ; 1 ; 6)$

d) $C j_{\text {Baru }}$

$-\left[\frac{\text { variabel asosiasi }}{\text { pivot }}\right] \times$ variabel keluar + xbaris lama

$=\quad[-40] \times(3 ; 2 ; 2.5 ; 0 ; 1 ; 0)+$ $(35 ; 50 ; 100 ; 0 ; 0 ; 0)$

$=(-85 ;-30 ; 0 ; 0 ;-40 ; 0)$

Iterasi I

Tabel $\mathrm{V}$ menyajikan hasil perhitungan dari iterasi I.

\begin{tabular}{lccccccc}
\multicolumn{7}{c}{ TABEL V } \\
ITERASI I \\
\hline Basis & $\mathrm{X}_{1}$ & $\mathrm{X}_{2}$ & $\mathrm{X}_{3}$ & $\mathrm{X}_{4}$ & $\mathrm{X}_{5}$ & $\mathrm{X}_{6}$ & $\mathrm{~b}$ \\
\hline $\mathrm{X}_{4}$ & 0.2 & -0.2 & 0 & 1 & -1.6 & 0 & 3 \\
$\mathrm{X}_{3}$ & 1.2 & 0.8 & 1 & 0 & 0.4 & 0 & 18 \\
$\mathrm{X}_{6}$ & 0.6 & 0.4 & 0 & 0 & -0.8 & 1 & 6 \\
$\mathrm{Cj}$ & -85 & -30 & 0 & 0 & -40 & 0 & \\
\hline
\end{tabular}

$$
\begin{aligned}
X_{1} & =0 \\
X_{2} & =0 \\
X_{3} & =18 \\
Z & =35(0)+50(0)+100(18) \\
& =1800
\end{aligned}
$$

D. Pengolahan Metode Simpleks Menggunakan Software Lingo 
Penyelesaian metode simpleks dapat dilakukan dengan cara perhitungan manual dan cara perhitungan menggunakan software. Gambar 1 adalah hasil dari pengolahan data menggunalan software Lingo. Hasil perhitungan menggunakan software Lingo yaitu jumlah iterasi penyelesaian ada 1 iterasi, nilai $\mathrm{X}_{1}$ dan $\mathrm{X}_{2}$ adalah 0 , serta nilai $\mathrm{X}_{3}$ adalah 18 . Nilai objektif atau nilai tujuan (Z) yaitu 1800 .

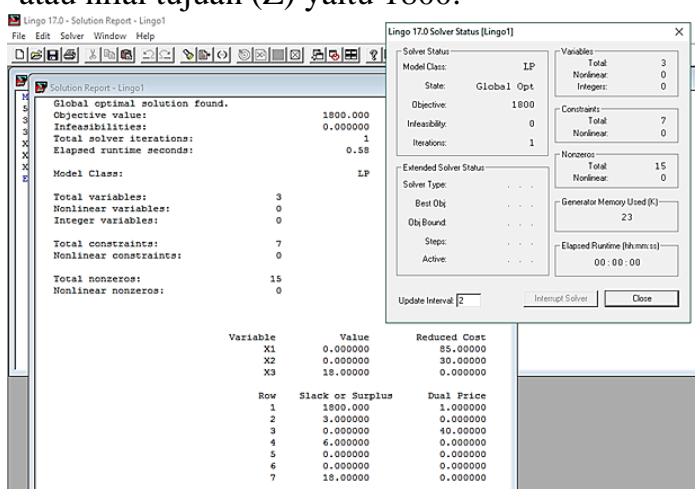

Gambar 1. Hasil Perhitungan Menggunakan Lingo

\section{E. Pengolahan Data Algoritma Greedy}

Berdasarkan tabel II yaitu nilai jarak tempat distribusi, maka didapatkan semua rute pendistribusian pada gambar 2 .

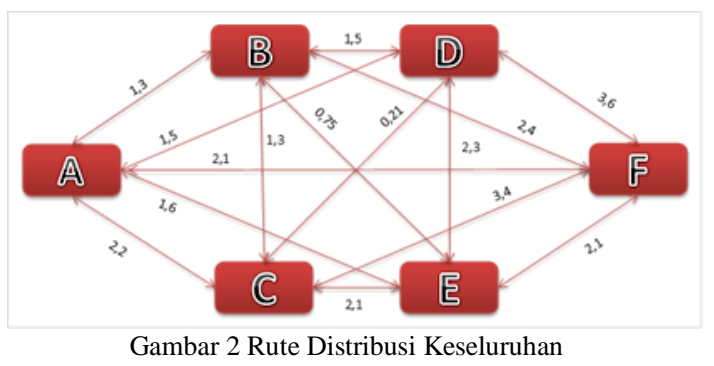

Gambar 3 merupakan operasi penentuan rute menggunakan algoritma greedy. Cara kerjanya yaitu mengambil titik dengan jarak terdekat dari titik asal.

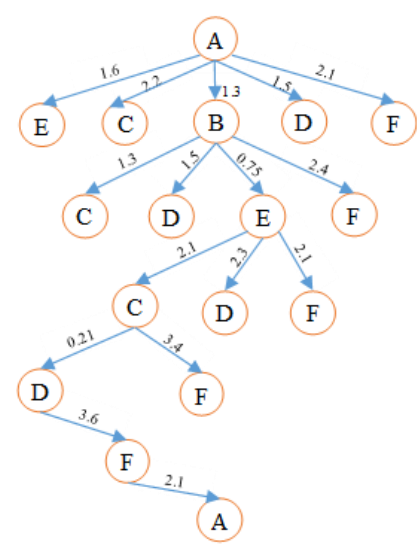

Gambar 3 Rute Distribusi Menggunakan Algoritma Greedy

Berdasarkan pengolahan algoritma greedy pada Gambar 3, maka didapatkan rute optimal seperti pada Gambar 4.

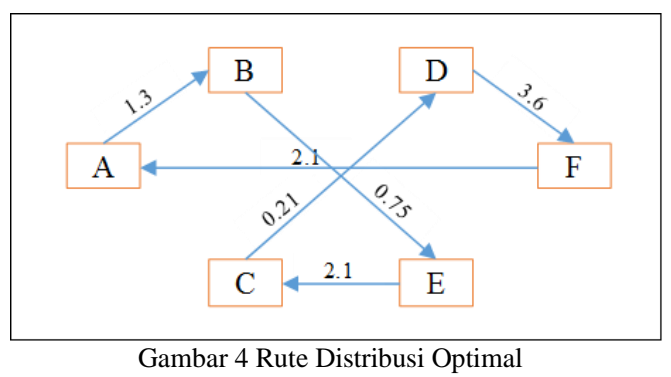

IV.PEMBAHASAN

\section{A. Pengolahan Metode Simpleks}

Hasil akhir pada Tabel V merupakan hasil akhir operasi hitung. Tabel iterasi I (Tabel V) tabel sudah optimal dan menemukan solusi, karena tidak ada $\mathrm{Cj}$ yang bernilai positif. Pada perhitungan Tabel V didapatkan nilai optimum sebagai berikut: $\mathrm{X}_{1}=0$, $\mathrm{X}_{2}=0$ dan nilai $\mathrm{X}_{3}=18$.

Agar pendapatan UMKM Semprong Amoundy dapat optimal dan maksimal, UMKM Sempong Amoundy dapat melakukan produksi kue semprong dengan ukuran box besar yang dinotasikan dengan $\mathrm{X}_{3}$ sebanyak 18 box per hari. Maka, pendapatan maksimal yang dicapai per hari yaitu :

$$
\begin{aligned}
& \mathrm{Z}=35 \mathrm{X}_{1}+50 \mathrm{X}_{2}+100 \mathrm{X}_{3} \\
& \mathrm{Z}=35(0)+50(0)+100(18) \\
& =1800 \text { dalam satuan ribuan rupiah/hari. } \\
& =\text { Rp. } 1,800,000 / \text { hari }
\end{aligned}
$$

Hal ini sejalan dengan perhitungan yang dilakukan menggunakan software Lingo. 
Perhitungan softaware Lingo pada gambar 1, menampilkan hasil sama dengan perhitungan manual, yaitu jumlah iterasi adalah 1 , dan nilai $\mathrm{X}_{1}$ $=0, X_{2}=0, X_{3}=18$. Nilai objektif (tujuan) yang dihasilkan adalah 1,800 dalam satuan ribuan rupiah. Perhitungan manual dan perhitungan software Lingo memiliki kesamaan nilai, hal ini dapat membuktikan bahwa perhitungan yang dilakukan sudah tepat.

\section{B. Pegolahan Algoritma Greedy}

Rute awal distribusi yang ditempuh oleh UMKM Amoundy tidak teragenda dan bersifat acak, maka digunakan salah satu rute sebagai perbandingan, rute distribusi pada Gambar 4, yaitu :

Rumah produksi Amoundy $\rightarrow$ Toko Denpasar $\rightarrow$ Toko Erik $\rightarrow$ Toko Aneka $\rightarrow$ Toko Bontot Dela Jaya $\rightarrow$ Outlet Oleh - oleh Karawang $\rightarrow$ Rumah produksi Amoundy.

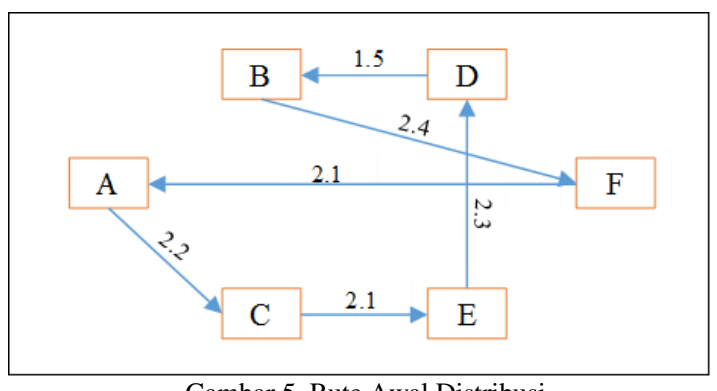

Gambar 5. Rute Awal Distribusi

Pemilik UMKM memberikan harga Rp. 2000,setiap $1 \mathrm{Km}$ jarak tempuh pendistribusian produk. Maka dengan rute pendistribusi yang seperti pada Gambar 5, jarak yang ditempuh yaitu $12.6 \mathrm{Km}$ dengan biaya sebesar Rp. 25,200.-. Tabel VI menyajikan jumlah biaya distribusi yang harus dikeluarkan jika menempuh rute pada Gambar 5.

TABEL VI BIAYA DISTRIBUSI

\begin{tabular}{lcc}
\hline \multicolumn{1}{c}{ Tempat Tujuan } & $\begin{array}{c}\text { Jarak } \\
(\mathbf{K m})\end{array}$ & $\begin{array}{c}\text { Cost } \\
(\mathbf{R p .})\end{array}$ \\
\hline Toko Denpasar & 2.2 & 4400 \\
Toko Erik & 2.1 & 4200 \\
Toko Aneka & 2.3 & 4600 \\
Toko Bontot Delajaya & 1.5 & 3000 \\
Oleh-oleh Karawang & 2.4 & 4800 \\
Rumah Produksi Amoundy & 2.1 & 4200 \\
Total & $\mathbf{1 2 . 6}$ & $\mathbf{2 5 2 0 0}$ \\
\hline
\end{tabular}

Setelah dilakukan penentuan rute distribusi menggunakan algoritma greedy, didapatkan rute optimal pada gambar 4. Maka panjang rute optimal yang dihasilkan algoritma greedy adalah $10.06 \mathrm{Km}$, biaya distribusi rute optimal seperti pada tabel VII.
TABEL VII

BIAYA DISTRIBUSI RUTE OPTIMAL

\begin{tabular}{lcc}
\hline \multicolumn{1}{c}{ Tempat Tujuan } & $\begin{array}{c}\text { Jarak } \\
(\mathbf{K m})\end{array}$ & $\begin{array}{c}\text { Cost } \\
(\mathbf{R p .})\end{array}$ \\
\hline Toko Bontot Delajaya & 1.3 & 2600 \\
Toko Erik & 0.75 & 1500 \\
Toko Denpasar & 2.1 & 4200 \\
Toko Aneka & 0.21 & 420 \\
Oleh-oleh Karawang & 3.6 & 7200 \\
Rumah Produksi Amoundy & 2.1 & 4200 \\
Total & $\mathbf{1 0 . 0 6}$ & $\mathbf{2 0 1 2 0}$ \\
\hline
\end{tabular}

Dari tabel VII diketahui jumlah biaya yang dikeluarkan oleh UMKM Amoundy jika melalui rute optimal adalah Rp. 20,120.

\section{KeSIMPULAN}

Penerapan aplikasi metode simpleks dan algoritma greedy di UMKM Amoundy dilakukan pada bagian produksi dan distribusi. Penelitian ini mengembangkan metode pemecahan masalah dengan Linear Programming: simplex method dan Travelling Salesman Problem: greedy algorithm.

Berdasarkan hasil penelitian yang dilakukan, maka disimpulkan dalam tiga simpulan, yang pertama yaitu nilai perhitungan simpleks untuk memaksimalkan produksi kue semprong Amoundy didapatkan hasil optimal $\mathrm{X}_{1}=0, \mathrm{X}_{2}=0$ dan $\mathrm{X}_{3}=$ 18 dengan nilai fungsi tujuan $=1,800$ (dalam ribuan rupiah). Yang kedua, Penulis menggunakan dua cara dalam pengolahan metode simpleks, yaitu perhitungan manual dan menggunakan software Lingo, dan didapatkan bahwa hasil dari kedua perhitungan tersebut bernilai sama. Yang ketiga, setelah dilakukan analisa, didapatkan rute terbaik untuk distribusi kue semprong yaitu rute dari Rumah Produksi Amoundy - Toko Bontot Delajaya - Toko Erik - Toko Denpasar - Toko Aneka - Outlet Oleh-oleh Karawang - Rumah Produksi Amoundy dengan panjang rute sepanjang $10,06 \mathrm{~km}$, dengan biaya Rp. 20,120.-. Hasil dari perhitungan algoritma greedy menunjukan adanya penurunan biaya distribusi sebesar $20.16 \%$.

Setiap metode memiliki kekurangan dan kelebihan masing-masing. Data pada penelitian ini dapat diselesaikan menggunakan metode grafik yang memilik proses lebih mudah. Namun, metode simpleks menghasilkan keputusan yang lebih global. Kekurangan penelitian ini yaitu tidak dilakukan analisis sensitivitas untuk mengevaluasi pengaruh perubahan parameter yang mempengaruhi pendapatan. Kekurangan lainnya yaitu tidak diketahui secara pasti biaya yang dikeluarkan untuk satu kali distribusi. Biaya yang digunakan pada penelitian ini merupakan biaya asumsi dan estimasi dari pemilik UMKM Amoundy. Algoritma greedy bukanlah metode yang menghasilkan keputusan paling optimal. Ada 
metode lain yang dapat digunakan untuk memecahkan masalah yang serupa dengan UMKM Amoundy, dan menghasilkan hasil rute distribusi yang lebih minimum.

Saran untuk penelitian selanjutnya dengan topik serupa, perlu dilakukan analisis sensitivitas untuk mengetahui akibat yang akan terjadi jika terdapat perubahan batasan. Penentuan rute distribusi dapat menggunakan algoritma lain yang memiliki tingkat keoptimalan lebih tinggi dari metode algoritma greedy.

\section{UCAPAN TERIMA KASIH}

Ucapan terima kasih penulis ucapkan kepada pihak UMKM Amoundy yang telah memberikan izin penelitian kepada peneliti.

\section{REFERENSI}

[1] W. E. Cahyono and D. Kunhadi, "Strategi Pengembangan UKM Gethuk Pisang Guna Melestarikan Makanan Tradisional," J. Media Tek. dan Sist. Ind., vol. 4, no. 1, p. 10, 2020, doi: 10.35194/jmtsi.v4i1.842.

[2] D. Sugiri, "Menyelamatkan Usaha Mikro, Kecil dan Menengah dari Dampak Pandemi Covid-19," Fokus Bisnis Media Pengkaj. Manaj. dan Akunt., vol. 19, no. 1 , pp. 76-86, 2020, doi: 10.32639/fokusbisnis.v19i1.575.

[3] E. B. Sanggrama, "Sebuah Solusi untuk Perkembangan UMKM di Indonesia," J. Akunt., vol. 12, no. 1, pp. 146-158, 2020, [Online]. Available: http://journal.maranatha.edu.

[4] R. P. Sari, D. T. Santoso, and D. Puspita, "Analisis Kesiapan UMKM Kabupaten Karawang Terhadap Adopsi Cloud Computing Dalam Konteks,"J@ti Undip J. Tek. Ind., vol. 15, no. 2, pp. 63-72, 2020.

[5] M. E. Uller, M. F. Sumual, and E. Nurali, "KARAKTERISTIK FISIKOKIMIA KUE SEMPRONG DARI CAMPURAN TEPUNG PISANG GOROHO (Musa acuminate, L) DAN TEPUNG SAGU (Metroxylon sago, Rottb)," Cocos, vol. 1, no. 5, 2017.

[6] L. R. Kristiana and T. Sunarni, “Aplikasi Pendekatan Theory of Constraints pada Maksimasi Throughput Produksi," J. Media Tek. dan Sist. Ind., vol. 2, no. 2, p. 11, 2018, doi: 10.35194/jmtsi.v2i2.399.

[7] B. S. Anggoro, R. M. Rosida, A. M. Mentari, C. D. Novitasari, and I. Yulista, "Profit Optimization Using Simplex Methods on Home Industry Bintang Bakery in Sukarame Bandar Lampung," J. Phys. Conf. Ser., vol. 1155 , no. 1,2019 , doi: 10.1088/17426596/1155/1/012010.

[8] N. Luh and G. Pivin, "Penerapan Metode Simpleks Untuk Optimalisasi Produksi Pada UKM Gerabah," Konf. Nas. Sist. Inform., vol. 3, pp. 208-213, 2017.

[9] Rico Ong; Alfionita N. R. Maran; Ardianto R. Lapik; Dimas M. B. Andita; Muhammad Fitra Kadir; Ricky V. Kindangen; Velly B. Latul; Matheus Supriyanto Rumetna; Tirsa Ninia Lina., "Maksimalisasi Keuntungan Pada Usaha Dagang Martabak Sucipto Menggunakan Metode Simpleks Dan POM-QM," J. Ris. Komput., vol. 6, no. 4, pp. 434-441, 2019.

[10] G. Lancia and P. Serafini, "Integer Linear Programming," vol. 4, no. 2, pp. 43-66, 2018, doi:
10.1007/978-3-319-63976-5_4.

[11] N. P. Krisnadewi and P. Y. Setiawan, "Optimalisasi Produksi pada Usaha Kecil Kripik Terry di Desa Nyanglan Kaja, Kecamatan Tembuku, Kabupaten Bangli," E-Jurnal Manaj. Unud, vol. 7, no. 11, pp. $6011-6040,2018$

[12] K. Hermanto, I. Adiasa, S. Altarisi, R. Rabani, and M. Amirul, "Rute Usulan Pendistribusian LPG Menggunakan Model Clustered Generalized Vehicle Routing Problem (CGVRP) dan Algoritma Dijkstra," Performa Media Ilm. Tek. Ind., vol. 19, no. 1, pp. 2736, 2020, doi: 10.20961/performa.19.1.41858.

[13] S. B. Prasetyo, "Analisis Efisiensi Distribusi Pemasaran Produk Dengan Metode Data Envelopment Analysis ( DEA )," J. Penelit. Ilmu Tek., vol. 8, no. 2, pp. 120-128, 2008.

[14] S. Rokhlinasari and A. Hidayat, "Al-Amwal, Volume 8, No. 2 Tahun 2016," Pengaruh Sist. Pengendali. Intern. Terhadap Kualitas Lap. Keuang. Pada Ban BJB Syariah Cirebon, vol. 8, no. 2, pp. 491-508, 2016.

[15] G. E. Yuliastuti, W. F. Mahmudy, and A. M. Rizki, "Implementation of Genetic Algorithm to Solving Travelling Salesman Problem with Time Window (TSP-TW) for Scheduling Tourist Destinations in Malang City," J. Inf. Technol. Comput. Sci., vol. 2, no. 1, pp. 1-10, 2017, doi: 10.25126/jitecs.20172122.

[16] Fatmawati, B. Prihandono, and E. Noviani, "Penyelesaian Travelling Salesman Problem Dengan Metode Tabu Search," Bul. Ilm. Mat. Stat. Dan Ter., vol. 04 no. 1 , no. 1 , pp. 17-24, 2015.

[17] A. Lukman, R. AR, and Nurhayati, "Penyelesaian Travelling Salesman Problem dengan Algoritma Greedy," vol. 04, no. December 2011, pp. 1-5, 2015, [Online]. Available: https://www.researchgate.net/publication/281113346 _Penyelesaian_Travelling_Salesman_Problem_deng an_Algoritma_Greedy.

[18] R. I. Bolaños, E. M. Toro O, and M. Granada E, "A population-based algorithm for the multi travelling salesman problem," Int. J. Ind. Eng. Comput., vol. 7, no. 2, pp. 245-256, 2016, doi: $10.5267 /$ j.ijiec.2015.10.005. 